\title{
Platón y la política como cuidado de las pasiones: sobre el tratamiento de la benevolencia en el Gorgias \\ Politics as care of the passions in Plato: on the treatment of benevolence in the Gorgias
}

\author{
Gustavo Gómez PÉRez \\ Pontificia Universidad Javeriana, Bogotá \\ gustavo-gomez@javeriana.edu.co
}

Recibido: 01/08/2019 - Aceptado: 30/10/2019

DOI https://doi.org/10.20318/fons.2019.4910

\begin{abstract}
Resumen
Sócrates, en el Gorgias (521d), afirma ser el único ateniense que practica en su tiempo el verdadero arte político. En este artículo se interpreta esta aserción desde el análisis del verbo $\theta \varepsilon \rho \alpha \pi \varepsilon u ́ \omega$, que en el contexto del diálogo puede traducirse como "servir", "cuidar" o "atender" (513e, 521a), y que alude primariamente al carácter terapéutico de la política en analogía con la medicina, aunque eventualmente también se usa para referir, por ejemplo, al entrenamiento de los caballos (516e). La tesis central es que Sócrates entiende el ejercicio de la política como cuidado de las pasiones, y de su relación con la benevolencia, que se define como una disposición afectiva básica y esencialmente política. A manera de conclusión, se plantea que el ejercicio socrático de la política depende de las posibilidades performativas del lenguaje, y está determinado por una tensión irreductible entre lo político y lo apolítico.
\end{abstract}

Palabras clave: Platón, Gorgias, política, pasiones, benevolencia

\begin{abstract}
In the Gorgias (521d), Socrates claims to be the only Athenian who practices the real art of politics in his time. The present paper interprets this assertion based on an analysis of the Greek

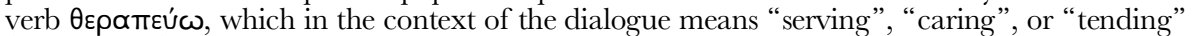
(513e, 521a). It alludes primarily to the therapeutic character of politics by analogy with medicine, but it also can refer to the training of horses (516e). Socrates understands the practice of politics as a way of taking care of the passions, and of their relation to goodwill, which is considered to be a necessary affective disposition that is inherently political. Socratic political $n$ practice depends on the performative possibilities of language. An irreducible tension between the political and the apolitical determines it.
\end{abstract}

Keywords: Plato, Gorgias, politics, passions, benevolence

ПНГН/FONS 4 (2019), 77-90

ISSN 2445-2297 www.uc3m.es/pege
G. Gómez Pérez, Platón y la política como cuidado DOI https://doi.org/10.20318/fons.2019.4910 


\section{La política socrática como cuidado de las pasiones}

Es bien conocida la intrigante afirmación de Sócrates, hacia el final del diálogo con Calicles en el Gorgias, según la cual él sería el único ateniense que en su tiempo practica verdaderamente el arte de la política ( $G r g .521 \mathrm{~d})$. Esta aserción se enmarca en una reflexión sobre lo que significa la buena vida, orientada por la búsqueda del conocimiento de la justicia y el bien común, en contraposición respecto de las opiniones corrientes, que tienden a sobrevalorar la importancia de la satisfacción irrestricta de deseos personales, la búsqueda del placer, la fama y la acumulación de bienes materiales. Esta reflexión responde a la advertencia de Calicles, quien aduce que la forma de vida filosófica defendida por Sócrates lo haría presa fácil en los tribunales, incapaz de defender sus bienes y su vida ante cualquiera que quisiera hacerle daño ( $G r g .482 c-486 d, 521 c)$. Llama particularmente la atención que en el curso de esta respuesta se subordina el valor de la propia vida al de la justicia y, en este sentido, se desestiman los riesgos que conlleva la práctica de la política primordial o genuina, aquella que supone decir siempre la verdad y obrar consecuentemente con ella, aun cuando esto pueda generar animadversión e impopularidad. De esta manera, la comprensión socrática de lo que significa una buena vida supone que la vida, concretamente la singularidad de la vida individual, no tiene un valor intrínseco, sino que depende de su cualificación en relación con la virtud ${ }^{1}$.

Cabe recordar que en la Apología se plantea que para el ser humano una vida sin examen no merece la pena ser vivida y, asimismo, se arguye que la mejor forma de vida es aquella dedicada a los discursos sobre la virtud y la justicia $(A p .38 a)^{2}$. Esto supone, por supuesto, una distinción entre la vida meramente biológica, que sería la vida en su mínima expresión, y la vida humana en su máxima expresión, o lo que sería su configuración más propia o esencial, que ha de ser comprendida como vida política. De acuerdo con esto, es lícito inferir que, paradójicamente, el criterio básico que define el valor de la vida humana coincide con el criterio que determina esta vida en su excelencia o virtud, es decir, en su máxima expresión (GóMEZ PÉREZ 2017, 188). En este sentido, el cuidado de la vida es el cuidado de la justicia, que se equipara, además, al cuidado de la salud del alma. En suma, para Sócrates no es necesario, ni deseable, defender a todo costo la propia vida, sino solamente la posibilidad de

\footnotetext{
${ }^{1} \mathrm{Al}$ respecto, es importante tener en cuenta, como lo plantea STAUFFER $(2006,149)$, que si bien Sócrates considera que la protección de la propia vida debe estar subordinada a la búsqueda de la virtud, esto no significa que desestime el valor de la protección de la vida en general. En este sentido, se entiende la valoración socrática de las artes que protegen la vida como "artes", lo que, a su vez, permite matizar en alguna medida, más allá de lo que se hace explícito en el diálogo, la valoración de la retórica como algo positivo desde el punto de vista filosófico.

${ }_{2}$ En este contexto, Sócrates afirma que el mayor bien para el hombre es "tener conversaciones cada

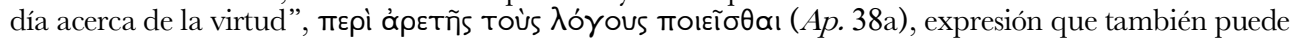
traducirse como "producir discursos sobre la virtud". En este sentido, se sugiere que la virtud del hombre está determinada fundamentalmente por el lenguaje, o que la acción virtuosa se enmarca en los límites del lenguaje o el habla (Gómez Pérez 2017).
} 
mantener una vida justa y virtuosa, es decir, una forma de vida buena, política ${ }^{3}$. Según veremos en lo que sigue, esta observación es importante para precisar la comprensión socrática de lo que significa, efectivamente, ejercer el arte de la política.

En el curso del Gorgias Sócrates proporciona importantes indicaciones concernientes a lo que significa el cuidado del alma. Primordialmente, cabe destacar la analogía entre el arte dedicado a la justicia, que es el mismo arte político, y la práctica de la medicina ${ }^{4}$. Esta comparación tiene como propósito distinguir entre un arte o disciplina soportada por la razón, orientada al conocimiento del objeto de estudio, y las prácticas o rutinas que simplemente se mueven en el reino de la apariencia 5 . De esta manera, Sócrates trata de demostrar que un arte genuino está basado en un conocimiento de la naturaleza, y que logra un resultado efectivamente útil o conveniente para el ser humano (JAEGER 2012, 804).

Uno de los argumentos esbozados en el diálogo defiende que el arte o el conocimiento es una fuente de poder en la medida en que produce un bien, esto es, un orden o proporción entre las partes ( Grg. 503e-504e). De este modo, la analogía entre política y medicina no solamente muestra que la política debe procurar la salud del alma, así como la medicina se ocupa de la salud del cuerpo, sino que en ambos casos se trata de artes que pretenden regular u ordenar la vida, ya sea, por una parte, la vida biológica o, por otra parte, la vida pública, aquella que se inscribe en el registro de lo político ${ }^{6}$. Sin embargo, la salud del alma es de un valor inconmensurable respecto de la salud del cuerpo por ser el alma, en últimas, el principio inteligible que define el sentido, la finalidad, de nuestras acciones. En otros términos, el alma es un principio de movimiento autónomo, mientras que el cuerpo está subordinado al alma. Esto explica, al menos en parte, la subordinación, en la que insiste Sócrates, de la vida individual o biológica respecto de la vida justa?

En este punto, vale la pena recordar que en el Fedón se define al alma como el principio vital que rige y da forma a las cosas (Phd. 105d-106d). Asimismo, es menes-

${ }^{3}$ De acuerdo con este planteamiento, la afirmación socrática de la vida virtuosa en menosprecio de la protección de la propia vida concuerda con los planteamientos de AGAMBEN (2010) sobre la biopolítica, y la distinción entre la vida que corresponde a una forma de vida política, ßíos, y la "nuda vida" que se suele identificar con la mera vida animal o biológica, $\zeta \omega n$.

${ }^{4}$ Según JaEger $(2012,804)$, en el Gorgias se considera a la medicina como paradigma de lo que significa un verdadero arte.

${ }^{5}$ Si bien en un comienzo Sócrates distingue entre dos tipos de arte político, el legislativo, que sería análogo a la gimnasia, y el judicial, que sería análogo a la medicina ( $G r g$. 464b-c), es claro que Sócrates pretendería practicar estos dos tipos de política (SEDLEY 2009, 59), y en lo que sigue nos concentraremos en el segundo tipo, el judicial, esto es, el que pretende corregir o curar el alma que está en la injusticia, y es análogo a la medicina.

${ }^{6}$ Sustituyendo la referencia al filósofo por la del político, esto es lo que sugiere JAEGER $(2012,804)$ cuando afirma lo siguiente: «Ambos [el médico y el filósofo] investigan el campo de la naturaleza a la que se consagran, no como un montón informe de hechos, sino con la mira de descubrir en la estructura natural del cuerpo o del alma el principio normativo que prescribe la conducta de ambos, la del médico y la del filósofo y educador».

${ }^{7}$ Esto significa que, contrario a lo que supone la perspectiva cartesiana, el cuerpo es animado por el alma, y esta puede subsistir en sí misma como principio de movimiento y acción (BROADIE 2001, 302306). 
ter asumir que el Estado es una extensión o amplificación del alma, como se insinúa en la República (368d-e), de manera que, como lo sugiere Giovanni FERRARI (2003, 61-62), hay una similitud proporcional según la cual la razón es al alma como el gobernante al Estado. Teniendo en cuenta la insistencia de Sócrates en que todo arte busca producir un orden entre elementos, que la analogía entre alma y Estado alude a una semejanza estructural entre las partes de cada objeto de estudio, y que los individuos son parte constitutiva del Estado en la medida en que participan en sus funciones sustantivas, es lícito inferir que esta comprensión del alma apunta a mostrar que nuestras acciones como ciudadanos son virtuosas en la medida en que armonizan con una comunidad política adecuadamente ordenada en torno a un bien común ${ }^{8}$.

Tanto la medicina como la política, en cuanto que refieren al gobierno de la vida, tratan de regular, imprimir orden, a un ser en movimiento, entendiendo el movimiento en un sentido muy amplio, por ejemplo, como capacidad de acción, generación, desarrollo y crecimiento. En este sentido se puede comprender que Sócrates sugiera que el propósito de la política es servir al Estado y los ciudadanos con el fin de hacerlos mejores ( $G r g ., 513 \mathrm{e})$. El verbo que se utiliza aquí para cualificar la actividad política es $\theta \varepsilon \rho \propto \pi \varepsilon u ́ \omega$, que puede traducirse por servir, cuidar, atender o proveer, también en el sentido médico de tratar o curar9 ${ }^{9}$ De acuerdo con esto, la política socrática es entendida como un trabajo terapéutico que asiste al adecuado funcionamiento de la comunidad política, tanto a sus individuos como al Estado en cuanto tal.

Ahora bien, si el arte de la política supone cuidado o atención, entonces comprende acciones que per se trascienden el interés meramente individual, que se consagran al otro o a los otros y que, además, conllevan, así sea muy sutilmente, una motivación afectiva: el deseo de beneficiar o favorecer. De esta manera, la política se ejerce fundamentalmente como comunicación o diálogo, si bien habría que entender la comunicación como apertura dialéctica a los otros en la búsqueda de un acuerdo sobre la verdad, particularmente la verdad sobre el bien común, y no como mera transmisión de información. La dialéctica puede, entonces, concebirse como una labor de esclarecimiento o restauración del médium que es el lenguaje, en el que se entretejen los lazos que dan unidad a la comunidad, lo común de la comunidad. Esta restauración del lenguaje consistiría en la explicitación de la significación política de palabras primordiales, esto es, palabras definitorias de la virtud humana como lo son "justicia", "bien" y "belleza", por ejemplo. El cuidado de la palabra redunda, pues, en cuidado del alma en cuanto que supone el cuidado de una vida común o, más precisamente, de la vida de una comunidad.

\footnotetext{
${ }^{8}$ Frente a la reticencia de Calicles a continuar en diálogo con Sócrates, este insiste en que la verdad sobre los asuntos que investigan, esto es, sobre el poder del arte político y la naturaleza de la vida justa, redunda en un bien común que, además, debe surgir de una investigación en común ( $G r g$. 505e-506a). En este sentido, se puede inferir que el bien político es un bien común, es decir, un bien que se reconoce como tal por los miembros de la comunidad.

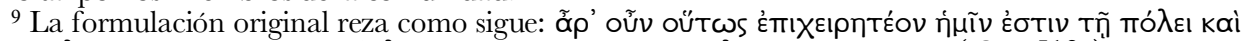

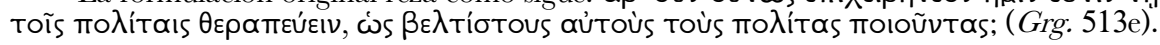


Así, pues, cuidar a una comunidad significa cuidar las condiciones que le dan sentido al discurso y a la comunicación política, así como también la comprensión de aquellas palabras primordiales que mueven a la comunidad política. Además, teniendo en cuenta que la significación primordial de las palabras es afectiva, el arte de la política puede ser entendido como un cuidado de los afectos, un esfuerzo continuo de rehabilitación o afinamiento de las orientaciones morales y afectivas que definen los contornos de una comunidad.

\section{La benevolencia y las condiciones del discurso político}

En el Gorgias, después del profético discurso de Calicles sobre la incompetencia de Sócrates para defender su vida ante un tribunal, Sócrates sugiere que ha encontrado en el acuerdo con su interlocutor la manera de demostrar la verdad de sus pensamientos, y afirma lo siguiente: "Pues observo que el que va a hacer una comprobación suficiente sobre si un alma vive rectamente o no, ha de tener tres cosas

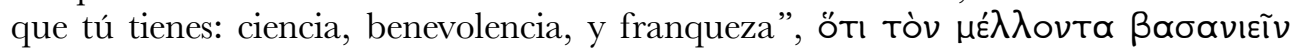

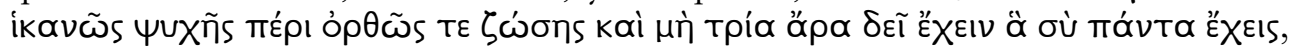

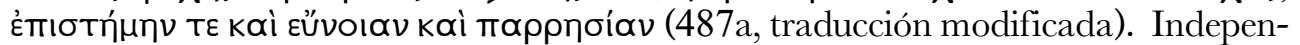
dientemente de la ironía que parece teñir esta intervención, a la luz de los planteamientos que Sócrates desarrolla en el curso del diálogo parece que ellas cualifican las condiciones que debe cumplir el discurso o el diálogo político para cumplir adecuadamente su finalidad propia, esto es, servir al cuidado u ordenamiento del alma en consonancia con el bien del Estado. Para aclarar este punto, cabe anotar que, inicialmente, la analogía con la medicina la presenta Sócrates en oposición a la culinaria, con miras a enfatizar la distinción entre el conocimiento orientado hacia lo que es verdaderamente bueno, una vida recta, y la apariencia que se basa en la mera sensación de placer. Así, parafraseando el pasaje apenas citado, el arte de la política debe estar orientado hacia un conocimiento efectivo de la justicia, del adecuado ordenamiento del alma y el Estado, y no, por ejemplo, la afirmación de un interés personal o ajeno al asunto mismo. Ciertamente, esta búsqueda debe estar basada en un diálogo veraz, lo que permitiría, por ejemplo, diagnosticar de manera precisa el alma del paciente, por ejemplo, o el mal que corrompe a la comunidad. Asimismo, la verdadera política debe procurar el bien del otro al que se aplica, o el bien común si se refiere al Estado, es decir, debe estar movido por buena voluntad, benevolencia.

La importancia de la veracidad y el conocimiento para el arte de la política se puede entender, también, a la luz de la tesis formulada más arriba sobre el carácter dialéctico de la política. En efecto, el conocimiento que está en juego refiere a la composición del alma, a la articulación de sus diferentes partes, lo que ha de aclararse primordialmente a partir de opiniones o creencias que se expresan, eminentemente, en el lenguaje. Asimismo, este examen de la opinión debe hacerse con base en una precisa comprensión de lo que es un alma justa. Por ello, la franqueza es necesaria en cuanto que la fiabilidad del diagnóstico depende de que las opiniones expresadas correspondan a lo que efectivamente se considera como verdadero, por ejemplo, 
respecto de la naturaleza de la justicia. En otras palabras, el acuerdo en relación con un bien común, aquel que expresaría de manera paradigmática la vocación de la política, no es efectivamente un acuerdo válido sin la presuposición de veracidad o franqueza por parte de los interlocutores.

Ahora bien, si se toma en consideración el contexto del pasaje citado, es posible advertir que al cualificar a Calicles como un interlocutor apto para el examen del alma y, por ende, para la práctica del arte de la política, Sócrates insinúa que la franqueza o la veracidad supone el interés en procurar el bien del otro, pues da a entender que se quiere compartir un conocimiento que se da por verdadero ${ }^{10}$. Por otra parte, Sócrates también sugiere indirectamente que el acuerdo de base sobre los fines perseguidos es indispensable para la búsqueda de la verdad en política, la verdad sobre la justicia, pues esta necesariamente se constituye como tal intersubjetivamente, lo que significa que tiende a ser una verdad polémica y exige el esfuerzo de reconciliar posiciones divergentes en la búsqueda de un bien común. En este sentido, es preciso afirmar que la verdad en política se pone a prueba en su dimensión dialógica y, por esta misma razón, exige un vínculo afectivo de base: la benevolencia.

Ahora bien, según se muestra en el diálogo, la benevolencia o la buena voluntad no tiene la notoriedad e intensidad que habitualmente se le atribuye a las pasiones o afecciones, lo que también ha notado Aristóteles ${ }^{11}$. En efecto, Sócrates reconoce la buena voluntad de Calicles en su exhortación a aprender de los aspectos prácticos de la política, por el hecho de que ha escuchado el mismo consejo dirigido a sus mejores amigos ( $G r g$ : 487b-e). Así, lo que en principio se muestra como una oposición obstinada y un intento por ridiculizar a Sócrates, quizás precisamente gracias a la vehemencia del tono de la intervención, revela buena voluntad, un velado interés por el bienestar de su contrincante. A la luz de esta interpretación del pasaje citado, se entiende que para Sócrates la benevolencia se revele como una disposición afectiva de base, que es presupuesto necesario para el diálogo político, pero que no es siempre evidente a simple vista. En otras palabras, si hay diálogo político es porque ya está dada la buena voluntad de las partes involucradas ${ }^{12}$.

La significación que en este caso adquiere el término "benevolencia”, züvous, amerita un análisis detallado. Por una parte, teniendo en cuenta las raíces del término griego, que remite en parte a las nociones de propósito, pensamiento o intención,

10 Vale la pena insistir en que, al aunar conocimiento, franqueza y benevolencia, Sócrates sugiere que el conocimiento político es un conocimiento que clama por su expresión pública, veraz y, así, supone la buena voluntad de compartir un bien, el saber sobre lo justo, que necesariamente es común, es un bien de interés público.

${ }^{11}$ Según Aristóteles, la benevolencia puede pasar inadvertida y no incluye ni la intensidad ni el deseo

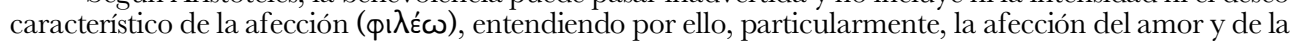
amistad, que supone el deseo vivo de la presencia del ser amado. Esto no significa que la benevolencia no suponga una especie de deseo distante, en cierto sentido desinteresado, por el otro, incluso un extraño (Arist. EN 1166b-1167a).

${ }^{12} \mathrm{En}$ su análisis de la benevolencia Aristóteles llama la atención sobre el hecho de que la amistad presupone la benevolencia ( $E N 1167$ a), asimismo, en este caso, podríamos decir que la amistad política, la posibilidad de un acuerdo político, requiere de la benevolencia como disposición afectiva previa. 
vóos, la benevolencia puede ser entendida como "buena intención”, en el sentido del propósito expreso de beneficiar a alguien. Por otra parte, como resulta evidente en la citada referencia a Calicles, cuya exhortación a Sócrates revela un tono de burla y desprecio ( $\mathrm{rrg}$. 485e-486a), la benevolencia no es patente de manera inequívoca en su expresión. Es importante tener en cuenta que a veces nuestros pensamientos, intenciones o propósitos no coinciden con lo que decimos a otros o a nosotros mismos: lo que realmente pensamos no necesariamente corresponde a lo que creemos que pensamos. En este sentido, la benevolencia podría referir a una especie de propósito o intención inconsciente o inadvertida que, sin embargo, en el diálogo o interacción propiamente política es siempre en alguna medida irreprimible. Al respecto, cabe recordar la distinción que establece Sócrates entre hacer lo que verdaderamente se quiere y hacer lo que a uno le parece ( $G r g$ : $469 \mathrm{c}-470 \mathrm{~b})$, pues en efecto, aunque siempre tendemos a estar en alguna medida bien dispuestos hacia los miembros de nuestra propia comunidad política, puede suceder, y de hecho sucede con frecuencia, que esta disposición afectiva pase inadvertida o parezca inexistente.

La benevolencia se presenta, pues, como una disposición afectiva fenomenológicamente ambigua, opaca o engañosa, que se puede encubrir incluso bajo la máscara de la animadversión. Si bien esta ambigüedad puede ser característica de diversas pasiones, como el amor y el odio, por ejemplo, parece que se trata de una característica más acentuada en la benevolencia en virtud de su carácter límite, y equívoco, como pasión: se trata de una disposición afectiva casi neutral, que en cierto sentido no es una pasión, puesto que en principio no pretende más que un bien desinteresado, independiente de algún interés o utilidad particular (Arist. EN1167a). Esta interpretación permite explicar parcialmente que la benevolencia pueda manifestarse, por decirlo así, sin anuencia expresa del agente. En contraste, emociones como el amor y el odio, quizás por su intensidad, son en general particularmente notorias para el agente mismo, de manera que este puede intervenir más fácilmente para tratar de controlar su manifestación exterior.

Para clarificar esta interpretación, puede ser de utilidad contrastar el significado ordinario del término "benevolencia", que suele entenderse como buena voluntad, es decir, como la voluntad de hacer el bien - entendiendo también la voluntad en el sentido de lo voluntario, lo que se realiza conscientemente - con los sentidos que resuenan en las raíces latinas del término benevolencia, que refieren también a un deseo del bien, a un querer bienintencionado, y no necesariamente a una expresión de la voluntad.

En este orden de ideas, se podría concebir la benevolencia como modalidad intencional en cierto sentido pasiva ${ }^{13}$, que no requiere de un reconocimiento temático o conceptual: la benevolencia sería así una variación del querer que refiere a un bien que puede aparecer como indeterminado para el sujeto, y que es eventualmente

\footnotetext{
${ }^{13}$ En relación con este punto, cabe recordar que en el curso de su análisis Aristóteles define a la benevolencia como una "amistad inactiva" (EN1167a).
} 
compatible con la presencia de otras modalidades intencionales como, por ejemplo, el desprecio, que es precisamente lo que parece ilustrar el ejemplo de Calicles. Al respecto, vale la pena anotar que algunos de estos rasgos de la benevolencia son patentes en la manera como se usa el término en diálogos como el Protágoras, el Fedro y la República.

En el Protágoras, por ejemplo, Pródico usa el término benevolencia para referir a la disposición afectiva, los buenos sentimientos, que deben predominar en las discusiones entre amigos, insistiendo en que estas discusiones no deben llegar al nivel de confrontación propio de la enemistad (Prt. 337b ). En el Fedro, por otra parte, al finalizar su primer discurso sobre el amor, Sócrates advierte que el cariño del amante no está marcado por el buen sentido o la benevolencia, sino por un apetito que demanda ser satisfecho (Phdr. 241c). En este caso, pues, se sobreentiende que la benevolencia debe primar sobre la pasión erótica para que esta sea recíprocamente benéfica. De esta manera se sugiere, además, que la benevolencia es un sutil lazo afectivo que se distingue claramente del apetito o el deseo sexual desenfrenado por su orientación moral, en cuanto que no busca instrumentalizar al otro en función de inclinaciones o intereses particulares. Finalmente, en la República se usa el término benevolencia en el contexto de la reflexión sobre la conducta de los guardianes frente a los enemigos, particularmente en una exhortación a mantener buena voluntad respecto de los pueblos griegos, refiriendo también al respeto por los muertos y los caídos en combate $(R .469 \mathrm{e}-470 \mathrm{a})^{14}$.

La benevolencia se presenta, así, como una especie de disposición afectivo-moral básica o incipiente que, por ejemplo, permitiría regular las relaciones entre amantes para que sean en beneficio mutuo, lo que significa que opera en cierto sentido a un nivel más fundamental que el del amor ${ }^{15}$. La benevolencia, por otra parte, entre rivales o enemigos representa un mínimo de respeto en virtud de, por lo menos, la promesa de un eventual beneficio recíproco: la pervivencia de una amistad o la posibilidad de una alianza futura. En este sentido, la benevolencia puede ser interpretada como un germen de la amistad o el amor, como lo sugiere Aristóteles (EN1167a).

A la luz de esta interpretación, es posible inferir que la importancia política de la benevolencia radica en su aparente neutralidad emotiva y su carácter intrínsecamente moral, su desinteresada orientación al bien ajeno y, particularmente, a un bien en cierto sentido todavía indeterminado por el sujeto. Ciertamente, como fue sugerido más arriba, es necesario que la benevolencia sea todavía un querer, una modalidad del afecto para que de alguna manera pueda orientar nuestra acción o, más precisamente, conmovernos para llevarnos a aspirar a un bien desligado de todo interés o utilidad específica. Sin embargo, en contraste con la inmediatez, densidad y

\footnotetext{
${ }^{14} \mathrm{El}$ sentido político de la benevolencia es particularmente notorio en este pasaje de la República, porque refiere a un lazo afectivo que debe primar incluso respecto de los enemigos.

${ }^{15}$ Retomando la relación insinuada entre benevolencia y amor en el Fedro, se podría aducir que en relación con el amor la benevolencia opera como un complemento moral fundamental, pues el amor bueno sería el que está fundamentado en la buena voluntad del amante.
} 
velocidad que caracterizan a los raptos de amor u odio, se puede concebir a la benevolencia como a una disposición afectiva ralentizada, distante, que se proyecta en el horizonte ideal de las relaciones potenciales o posibles, o en los trazos de los vínculos olvidados o inadvertidos. En últimas, y quizás llevando un poco lejos esta interpretación, se podría afirmar que la benevolencia se revela como una modalidad del querer que se aferra, por decirlo así, a la pura apertura del deseo y la referencia a un bien siempre por venir, que necesariamente pertenecerá a otro: a otro yo, o a otro que ya no será un yo, a otro que nunca será presente.

Desde esta interpretación de la noción de benevolencia se puede especificar con mayor claridad y profundidad en qué sentido conocimiento y franqueza se conjugan en el arte de la política. En efecto, según se muestra en la argumentación precedente, la benevolencia sería una disposición afectiva que hace patente la resonancia entre el bien ajeno y el bien propio en virtud de un vínculo indeterminado. De acuerdo con esto, se podría afirmar que el conocimiento que está en juego en la política, y que se hace patente en la benevolencia, es el conocimiento de la co-pertenencia y codependencia que nos liga ineludiblemente a una comunidad política ${ }^{16}$, de modo que el bien del otro redunda en un bien propio, lo que define el orden que debe primar en el alma justa ( $G r g$. 506a). Por esta razón, la veracidad es fundamental para la política, pues sin ella no es posible determinar la fragilidad o fortaleza del vínculo que nos une a la comunidad, esto es, el verdadero estado del alma en relación con la justicia.

En este orden de ideas, el verdadero político debe saber reconocer la veracidad o franqueza de una expresión de benevolencia, más allá de las máscaras que tienden a encubrirla en la comunicación ordinaria, pues se trata de un afecto difícil de interpretar o reconocer en la medialidad sensible de su expresión. Además, el verdadero político debe saber cómo fomentar o favorecer el desarrollo de la benevolencia como punto de partida para la constitución de una comunidad política sana u ordenada.

\section{Las paradojas de la política socrática y los límites de lo político}

Si bien Sócrates parece convencido de que tras la reprimenda de Calicles hay buena voluntad, una buena intención, el diálogo no culmina con un acuerdo pleno y explícito sobre el concepto de justicia. Al ser refutado, Calicles intenta terminar abruptamente el diálogo y solamente continúa, forzadamente, obligado por la intercesión de Gorgias y la insistencia de Sócrates en mantener en lo posible la forma de la conversación ( $G r g$. 505d). En otras palabras, la pretendida validez lógica de los argumentos socráticos no basta para convencer a Calicles de la inconveniencia de sus

\footnotetext{
16 Esto es particularmente claro si, como lo afirma Sócrates, todo arte apunta a producir o promover orden o proporción entre elementos ( $G r g: 503 \mathrm{~d}-504 \mathrm{a}$ ), lo que significa que la política debe conocer cómo se deben relacionar entre sí los ciudadanos. En otras palabras, la política es un saber concerniente a las correlaciones entre los miembros de la comunidad.
} 
posiciones, y la comunicación se mantiene casi como pura formalidad, y esto gracias a la coerción del auditorio ${ }^{17}$.

Así, pues, Sócrates concluye el diálogo con un mito que pretende exponer la verdad sobre el destino último de las almas en relación con la justicia ( $\mathrm{rg}$. 523a527e), probablemente buscando con ello agotar instancias para la persuasión en un momento en el que el interlocutor podría ser más proclive a escuchar a este tipo de discurso, toda vez que ya se ha transitado el camino de la dialéctica ${ }^{18}$.

Esta lectura del final del diálogo sirve de punto de partida para precisar dos aspectos notables de la función del discurso en el ámbito de la política socrática. En primer lugar, como fue sugerido en la primera sección, cabe recordar que la acción política, según lo sugiere Sócrates, se restringe a lo que es posible hacer en el ámbito del discurso y la comunicación dialéctica. En este sentido, para comprender adecuadamente la naturaleza de la actividad política es necesario prestar atención a la dimensión performativa del lenguaje. En efecto, aunque el mito sobre el ajusticiamiento de las almas puede ser leído simplemente como una narración ficcional que pretende ilustrar desde un ángulo diverso algunas de las tesis ya propuestas en el curso del diálogo, este también puede interpretarse como una sutil advertencia que revela el tipo de castigo que le espera a quien, como presuntamente sucede con Calicles, se resiste a asumir una forma de vida basada en la búsqueda de la justicia ${ }^{19}$. En otras palabras, la advertencia de Sócrates intenta, por decirlo así, usar el discurso para forzar a su interlocutor a cambiar su opinión sobre la justicia y lo que significa una buena vida ${ }^{20}$. En segundo lugar, y en relación con lo anterior, cabe anotar que la dimensión performativa del lenguaje político está orientada a una especie de adiestramiento de los afectos, de manera que estos armonicen con un talante benevolente. Según la argumentación que sigue, esta orientación del discurso político supone, en cierto sentido, una transgresión de lo político, un desplazamiento hacia lo apolítico: la remisión de lo político, de la justicia, a un poder o capacidad que desborda el poder de un arte propiamente humano.

Como lo sugiere el mito en cuestión, el arte de la política, del ajusticiamiento del alma, debe observarla en su desnudez al momento de la muerte ( $G r g .523 a-524 a)$, lo

\footnotetext{
${ }^{17}$ Vale la pena anotar, de acuerdo con lo planteado por DodDs $(1959,30)$, que desde un punto de vista puramente lógico o de validez argumentativa, los razonamientos expuestos en el diálogo son con frecuencia poco convincentes o falaces.

${ }^{18}$ En este sentido, el mito puede ser leído como un refuerzo retórico de cuestiones ya desarrolladas dialécticamente, en consonancia con lo que plantea SEDLEY (2009), quien en su lectura del mito enfatiza que el mismo Sócrates extrae del mito dos lecciones básicas, en primer lugar, su resonancia con las conclusiones derivadas de la conversación precedente y, seguidamente, la indicación de cómo puede Calicles evitar la condena de su alma.

${ }^{19}$ Según la explicación de SEDLEY $(2009,64)$, este castigo puede ser en cierto sentido el ejercicio mismo de la refutación que, por ejemplo, puede hacer patente cómo una forma de vida dedicada a la satisfacción indiscriminada de apetitos es indeseable.

${ }^{20}$ En este sentido, la afirmación de Sócrates según la cual seguramente Calicles despreciará este mito, y lo interpretará como superstición propia de señoras ancianas ( $G r g$. 527a), no hace más que reforzar la fuerza de la amenaza: que Sócrates insista en la advertencia a pesar de que es consciente de su ineficacia, refuerza la idea de que efectivamente habla por deber con la verdad.
} 
que en principio puede ser una forma de aludir a su vulnerabilidad ineludible frente a la mirada de la comunidad - incluyendo a la comunidad en su proyección hacia un futuro indefinido, la comunidad por venir - su subordinación a un logos común que se impone como una ley divina que rige por encima de toda voluntad personal, y cuyo dominio se extiende en el horizonte de la historia de un pueblo. En otras palabras, la fuerza performativa del discurso pone en evidencia un sentido que surge en un entramado de significaciones de orden afectivo y moral, cuyo sentido escapa a toda voluntad o interés individual, incluyendo la voluntad del gobernante, de manera que su fuente y finalidad se revelan en últimas como sagradas, como ancladas a un pasado mítico.

Para que una amenaza o una promesa sea "políticamente" efectiva, esto es, para que genere una transformación en el alma del paciente, en su carácter, es necesario que ella de voz a una autoridad legítima, con un poder que se revela en lo pertinente como incuestionable. Al respecto, es importante tener en cuenta que tanto las jerarquías sociales y las relaciones de poder, como los atributos que hacen amables o deseables a las cosas, derivan su significado y su valor de principios encarnados en la vida de la comunidad como un todo. De acuerdo con esto, la política entendida como cuidado del alma para procurar su mejoramiento, o eventualmente preservar su salud, depende de una especie de acuerdo subterráneo entre los individuos - por ejemplo, entre el gobernante y el gobernado - una relación de coordinación mutua que, en últimas, está subordinada a lazos afectivos y morales, y que remiten a una instancia que es trascendente respecto de la política misma en su constitución legal o jurídica ${ }^{21}$. Desde esta perspectiva, es lícito afirmar que la fuerza performativa del lenguaje político deriva de un poder que es en cierto sentido exterior a lo político, a saber, el poder de los afectos. Así, pues, si asumimos que los raptos de pasión evocan la subordinación a un poder divino, se entiende que Sócrates termine su intervención con un mito que alude a la instancia divina que determina la aplicación de la justicia.

En este contexto, cabe insistir en la importancia de la benevolencia entendida como la inclinación a querer el bien incluso del extraño, o a sentir el bien de un extraño como propio, lo que supone el reconocimiento o aceptación de la co-dependencia que obliga a la búsqueda de un bien compartido en una comunidad que excede los límites de la familia o la aldea. De acuerdo con esto, la benevolencia se revela como la disposición afectiva que es política en un sentido emblemático, que desborda los límites de lo jurídico. Asimismo, siguiendo esta línea argumentativa, la benevolencia puede ser comprendida como una disposición afectiva que nos permite ir más allá de nosotros mismos, un afecto que nos da la posibilidad de suspender el juicio respecto

${ }^{21}$ Como bien lo expresa Diego Garrocho apelando a una lectura de la tradición filosófica en su conjunto, la política se constituye como tal desde una comunidad de la pasión: «Desde la Antigua Grecia hasta Nietzsche, existen testimonios filosóficos en los que se advierte cómo la verdadera constitución política - la politeia - pasaría antes que por las leyes y su instrucción jurídica, por aquella comunidad o koinonía que se establece entre aquellos que son capaces de compartir una misma pasión. La comunidad política es siempre una comunidad del pathos» (GARROCHO 2019, 115). 
del interés individual o, mejor aún, es el tipo de afecto que define lo que es una acción libre políticamente: una acción que procura el bien del otro o los otros y, en últimas, el bien del Estado, independientemente de las tendencias egoístas que suelen imponer ordinariamente las pasiones.

Este último punto se puede clarificar en relación con el análisis del castigo que lleva a cabo Sócrates, y según el cual para que un castigo cumpla su propósito primordial, este debe ser reconocido como beneficioso o justo por el imputado ( $G r g .525 \mathrm{a}-\mathrm{b})$. En efecto, políticamente, el castigo solamente tiene sentido si logra llevar a la persona a un reconocimiento del mal infligido a la comunidad y, por esta vía, a una clara identificación de lo que es el bien, y del hecho de que el bien común prima sobre el mal que, en un sentido muy restringido, supone el dolor del castigo o el amor por el bienestar propio $^{22}$.

Ahora bien, si la benevolencia consiste en un afecto cuya fuerza deriva del trasfondo afectivo y moral que define los ejes axiológicos de una comunidad, y que en cierto sentido ya está siempre presupuesto en toda interacción política formalmente definida como tal, entonces el tratamiento al que alude Sócrates como propio de la política no puede pretender tanto inducir o generar la benevolencia como develarla o explicitarla como condición de posibilidad para el mejoramiento del orden social, o la preservación del mismo cuando este ya es justo, y para el proceso de perfeccionamiento del individuo en cuanto que ciudadano. Ciertamente, esta comprensión del arte político estaría en consonancia con los principios de la mayéutica socrática.

De este modo, el proceso terapéutico puede ser interpretado como un esfuerzo de armonización entre el yo temático, voluntario y personal, y el yo pre-temático y prepersonal que está indisolublemente anclado a una agencia colectiva. Al respecto, cabe recordar que Sócrates insiste recurrentemente en el hecho de que la justicia, así como la verdad, representan un poder frente al cual no tenemos más alternativa que plegarnos.

La alusión al adiestramiento de los caballos, entendido como una especie de terapéutica ( $\mathrm{rg} .516 \mathrm{e}$ ), sirve de ejemplo para comprender lo que haría el verdadero arte de la política con el alma que está desorientada, o en desarmonía, para llevarla a una composición armónica en relación con los fines de la comunidad. Así como el que adiestra caballos debe lograr imponer en ellos un orden que les permita servir a los fines que persigue esta disciplina (el adiestramiento de caballos), así mismo la política debe generar ciudadanos dóciles y afines a la ley de la ciudad. En este sentido, afirma Sócrates, ninguno de los renombrados políticos de Atenas, particularmente ninguno de los que admira Calicles ${ }^{23}$, ha sido exitoso como político, pues en últimas ellos han

\footnotetext{
${ }^{22}$ De acuerdo con esto, el castigo de la refutación dialéctica, o el medio de la persuasión que surge de la "verdadera" retórica política, se diferencian radicalmente de los mecanismos tradicionales de castigo, como la prisión, la multa, el exilio o la muerte (SEDLEY 2009, 62-66).

${ }^{23}$ Sócrates refiere en particular a Pericles, Cimón, Temístocles y Milcíades ( $\left.G r g .516 a-e\right)$. Cómo lo aclara STAUfFer (2006, 151-153), la lista que da Sócrates tiene un claro propósito retórico, que no necesariamente coincide con detalles históricos, pues incluye específicamente a "héroes" de Calicles.
} 
terminado experimentando la oposición y el castigo por parte de sus conciudadanos. Sin embargo, siguiendo esta línea argumentativa, es importante llamar la atención sobre el hecho de que Sócrates mismo parece haber fallado estrepitosamente en su labor como político, pues termina siendo condenado a muerte por la ciudad de Atenas $^{24}$.

A la luz de estas consideraciones, parece que o bien Sócrates miente cuando afirma que es el único verdadero político de Atenas, pues no logró hacer de Atenas una ciudad más dócil y obediente a su "verdadero" gobernante, en este caso, él mismo en cuanto autoproclamado político, o lo que se tiene en mente aquí como verdadera política no es otra cosa que una especie de terapia auxiliar para contribuir al bien común, teniendo en cuenta que la vida política responde a un orden que se impone de suyo desde la agencia colectiva que cristaliza en el Estado.

Esta lectura supone en principio dos alternativas para comprender los límites del poder del arte político, una según la cual la política sería un arte circunscrito a los límites de la agencia y la voluntad humanas, pero que solamente logra aplicarse parcialmente con algún éxito en individuos particulares y no en comunidades o grupos $^{25}$, o se trata de un arte cuya eficacia depende en últimas de una agencia colectiva, respecto del cual la acción humana individual solamente puede ser subordinada. En este sentido, no es del todo claro que pueda considerarse a la política como arte. Esta última interpretación puede ser reafirmada con base en lo que se dice en el mito final sobre la justicia respecto al alma incurable ( $G r g .525 \mathrm{~b}-\mathrm{d}$ ), la cual ya no puede obtener ningún beneficio propio del castigo eterno, pero al ser castigada termina aportando al bien común, pues sirve como ejemplo para los otros miembros de la comunidad de aquello que no se debe hacer, y de lo que le espera a quiénes viven su vida en la injusticia. En efecto, el mito muestra que más allá de los resultados o evaluaciones parciales que podamos hacer de las acciones desde un punto de vista particular, desde una perspectiva más amplia o general, como aquella que podríamos atribuir a la historia de una nación, por ejemplo, las acciones o hechos particulares necesariamente terminan contribuyendo a un bien común o universal. Por supuesto, esta lectura supone el compromiso con una concepción teleológico-metafísica de la historia que no deja de ser problemática.

Más allá de estas interpretaciones del asunto, queda quizás una tercera posibilidad, a saber, la de interpretar la verdadera política que profesa Sócrates como una política imposible, o esencialmente apolítica, una política basada en la capacidad para domesticar o adiestrar a lo humano desde el registro limitado de la acción humana. Esta alternativa supone aceptar que se establezcan diferencias esenciales entre

\footnotetext{
${ }^{24}$ Esta conclusión puede ser matizada si, como lo sugiere STAUfFER (2006, 151), se acepta que Sócrates al menos ha demostrado la capacidad para mejorar a algunos ciudadanos en la vida privada, lo que significa que estaría más cualificado para el ejercicio de la política en un sentido público. En este caso, habría que preguntar por qué Sócrates no se involucró más en la vida pública.

${ }^{25}$ Es posible afirmar esta conclusión solamente si se asume que Sócrates efectivamente logró hacer más justos a algunos individuos.
} 
gobernantes y gobernados, una división de lo humano basada en un poder humano que se erige como sobre-humano, es decir, una división esencial o de naturaleza entre los miembros de una misma comunidad política.

\section{Bibliografía}

Agamben, G. (2010), Homo Sacer. El poder soberano y la nuda vida, I, trad. A. Gimeno Cuspinera, Valencia.

Aristóteles (1985), Ética Nicomáquea, trad. J. Palli Bonet, Madrid.

Broadie, S. (2001), «Soul and Body in Plato and Descartes», Proceedings of the Aristotelian Society 101, 295-308.

Dodds, E.R. (1959), Gorgias. A Revised Text with Introduction and Commentary, London.

Ferrari, G. (2003), City and soul in Plato's Republic, Chicago.

Garrocho, D. (2019), Sobre la nostalgia, Madrid.

Gómez Pérez, G. (2017), «Sócrates: gesto y palabra política», Universitas Philosophica 34 (69), 173-94.

Jaeger, W.W. (2012), Paideia. Los ideales de la cultura griega, México.

Platón (1985), Protágoras, en Diálogos, I, trad. C. García Güal, Madrid, 487-589.

Platón (1987), Gorgias, en Diálogos, II, trad. J. Calonge, Madrid, 7-146.

Platón (1988a), Fedón, en Diálogos, III, trad. C. García Güal, Madrid, 7-142.

Platón (1988b), Fedro, en Diálogos, III, trad. E. Lledó Iñigo, Madrid, 289-413.

Platón (1988c), República, en Diálogos, IV, trad. C. Eggers Lan, Madrid.

Platón (2011), Apología de Sócrates, en Diálogos, I, trad. J. Calonge, Madrid, 137-186.

Sedley, D. (2009), «Myth, Punishment and Politics in the Gorgias», en C. Partenie (ed.), Plato's Myth, Cambridge, UK, 51-76.

Stauffer, D. (2006), The Unity of Plato's Gorgias: Rhetoric, Justice, and the Philosophic Life, Cambridge. 